\title{
RESCUING RELIGIOUS NON-REALISM FROM CUPITT
}

\author{
RUTH WALKER \\ University of Waikato, Hamilton, New Zealand
}

\begin{abstract}
Don Cupitt's version of religious non-realism based as it is on linguistic constructivism, radical relativism and the view that culture forms human nature has been attacked with devastating effect by realists in the last few years. I argue that there is another strand in Cupitt's thinking, his biological naturalism, that supports a different version of religious non-realism and that he failed to see this possibility because of his global non-realism and commitment to the strong programme in the sociology of scientific knowledge. Cupitt's biological naturalism should have led smoothly into evolutionary psychology, which has an account of religious belief that supports a non-realist interpretation. Evolutionary psychology shows that religious beliefs are natural, normal and about matters of the deepest significance to humans. They gain their character from the operation of evolved structures of the mind and cannot be reduced to other sorts of belief. I argue that the form of religious nonrealism that emerges from taking biological naturalism seriously has a future because it respects the nature of religious belief and seeks to build on its capacity as a unique source of meaning in people's lives. There is also enough common ground with religious realism for there to be genuine dialogue between the two.
\end{abstract}

\section{INTRODUCTION}

Most people interested in religious non-realism associate the term with Don Cupitt who has an extensive popular following that has spawned a movement, Sea of Faith, dedicated to exploring radical non-realist alternatives to orthodox realist Christianity. The debate between realists and non-realists with respect to religious beliefs is about whether religious claims should be interpreted - in accordance with their 'surface structure' - as assertions about aspects of 'mind-independent' reality, or whether they should be interpreted as playing some other role (for example, as assertions about a 'socially constructed' mythic realm, or even as direct expressions of a community's most fundamental values). Cupitt has consistently advocated versions of the latter interpretation. There is no doubt that Cupitt tapped into a reservoir of unease in the mainstream denominations of Christianity in the 1980s and 1990s as people found it increasingly difficult to assent to some of the supernatural aspects of religious beliefs. These were people who still had strong religious 
commitments, who saw the value of Christianity as Jesus lived it even as they lost their belief in Jesus' divinity. They sought to reform Christianity rather than to leave it and Cupitt was their spokesman. From his early efforts in Taking Leave of God ${ }^{1}$ to formulate an intellectually satisfactory alternative to religious realism until the present day he has offered a perspective on the debate between realists and non-realists that cannot be ignored.

Unfortunately, Cupitt's standing in the philosophical world is not high and it has been easy for religious realists such as Byrne to offer excellent and decisive arguments against the forms of non-realism he has advocated in the past twenty-five years. ${ }^{2}$ Cupitt's non-realism has always been grounded in what he terms 'culturalism', the view that human nature, religious beliefs and all social practices are infinitely malleable by culture. Language is the means for shaping both how the world appears to people and, more extremely, how the world actually is. His culturalism makes him a radical relativist, an advocate of the strong programme in the sociology of scientific knowledge and an ardent post-modernist. These are all difficult positions to defend and I do not seek to do so. According to Byrne, Cupitt holds the view that language is not just a truth-bearer but also a truth-maker. He argues that the world has no determinate features until these are created by language. Statements do not merely report a state of affairs that obtains; they bring it about. Byrne regards that position as requiring an appeal to magic. ${ }^{3}$ If religious nonrealism could be supported only by such an approach then it would be in desperate trouble.

There is, however, another element to Cupitt's thinking that his commitment to culturalism obscures and that shows considerable promise for developing into an alternative basis for religious non-realism. That is the strand of thinking that Cupitt labels biological naturalism. Cupitt's background in biology made him aware early on in his work that evolution played a vital role in the construction of human psychology and in the existence of the linguistic capacity to which he attributes so much. He recognized early that as biological organisms humans had a unique perspective on the world that they could not transcend - except, he thought, through culture. But that exception brings out the crux of the problem. The culturalism that Cupitt argues is a causal force shaping thought and reality cannot bear the weight he puts on it. Much of what he attributes to culture turns out to belong to biology. Cupitt keeps culture as the dominant causal force and biology in a subordinate role with barely any causal power when he should almost reverse their respective positions. In the following sections I shall disentangle the biology from Cupitt's culturalist framework and show how it is possible to maintain religious non-realism as a live option for the interpretation of religious belief using insights from developments in evolutionary biology and psychology. In doing so I shall show that, in addition to the philosophical 
problems Byrne has identified, Cupitt has simply fallen into errors of fact that fatally undermine his version of religious non-realism.

The first step is to examine the relationship between culture and biology as Cupitt understands it and then provide an account of how developments in evolutionary psychology have led to a quite different interpretation of culture that is relevant to a more empirically robust theory of religion. Then it is useful to explore the reasons for Cupitt's failure to realize the significance of evolutionary psychology for his own work in order to understand more fully what is at stake for those sympathetic to non-realism. With that background in place I shall then show that the strand in Cupitt's work labelled biological naturalism is best given content by evolutionary psychology and how it is possible to restore religious non-realism as an alternative to religious realism by giving it a biological base. It is particularly important to note that the version of non-realism supported by evolutionary psychology recognizes the normality of religious beliefs and their significance in human life. At the very least that opens up the possibility of a fruitful conversation between religious realists and religious non-realists.

\section{CULTURALISM AND BIOLOGY}

Until the early 1990s in the social sciences, culture was generally seen as an independent causal force in shaping human nature and the content, if not the structure, of the human mind. By culture most theorists, including Cupitt, meant transmitted culture, that which is passed vertically from generation to generation or horizontally within generations. Everything from food technology to folklore can be transmitted. Fashions, songs and slang spread rapidly through the population and generally the stock of cultural representations available to people is very large. It is easy to think that the culture available to people contributes to their identity, making them distinct from people in other cultures. Theorists of religion who correctly regard religion as a cultural product have also naturally assumed that culture has causal properties in determining what sort of person an individual will become in any particular society. Biology in this model, labelled by Tooby and Cosmides the 'Standard Social Science Model', provides the body but very little of psychological importance. The mind is seen as something close to a blank slate that is both written on and organized by culture that is external to the individual. ${ }^{4}$ Cupitt, in keeping with his radical approach, has always maintained a very significant role for culture in the moulding of the individual. Indeed, it is culture mediated by language that forms the basis of a cultural relativism so strong that he regards members of different cultures as seeing 'different worlds'. ${ }^{5}$ In case his readers are tempted to think that he means that metaphorically he later adds that culture forms 'perceptual 
and cognitive capacities' so that there are no purely biological responses (Creation, p. 163). He claims, without any supporting evidence, that 'even the way our visual system works is subject to historical change' (Creation, p. 100).

Emotions are, in Cupitt's view, similarly culturally determined. They are created by stories, constructed in language and can be identified only to the extent that they can be described. 'Cultural codes' produce emotions. ${ }^{6}$ Even human sexuality is a 'cultural fiction' (Story, p. 155). Biology provides something of an amorphous blob that has to be worked into shape by culture and language. It has few determinate features independent of the modification undertaken by culture. Cupitt claims that '... there is no purely biological level of life, prior to its expression in the sign' (Creation, p. 98) and that 'the cultural has grown bigger and bigger while the natural has grown smaller and smaller'. ${ }^{7}$ For Cupitt it is obvious that perceptual, cognitive and emotional systems cannot function without the operation of culture on them. It is equally clear to him that what is perceived, thought and felt is determined by the historical setting and geographical location of the individual. There is nothing significant about human nature that is universally shared by way of a common biology. Cupitt rests his entire case for religious non-realism on the fact of culturalism, which is unfortunate given the robust evidence available now for a somewhat reduced role for culture in the making of a human being and a greatly enlarged one for biology.

Cupitt's line of reasoning is this: if culturalism is true then the human mind and human nature are extensively malleable and all cultural products can be changed. Religious belief is a cultural product so it too can be changed and it can be changed radically because culture, as an independent causal force, is capable of bringing about whatever radical change people choose. (Cupitt is primarily interested in what reforms people should explicitly select). Religious belief is wholly contingent on the historical conditions obtaining at the time and now that conditions have changed we (Cupitt uses the personal pronoun a great deal) should change our out of date religious beliefs in a divine order and supernatural beings. Byrne correctly identifies Cupitt as a global non-realist who consistently rejects realist interpretations of any domain of discourse. ${ }^{8}$ His religious non-realism appears to be a form of expressivism about human values.

However, the work of evolutionary psychologists and anthropologists such as Boyer, Sperber, Barrett, Tooby and Cosmides shows that there are good reasons for rejecting the idea that the various evolved features of the mind have minimal influence on the formation of culture and cultural products such as religious beliefs. I shall now examine this work in more detail and show how it affects the possibilities for interpreting religious belief. 


\section{EVOLUTIONARY PSYCHOLOGY}

In the early 1980s Cupitt was right to shun the work of evolutionary psychologists who were still in the grip of an over-enthusiastic sociobiology that claimed far too much, replaced cultural determinism with biological determinism and had only the most tenuous connection to experimental evidence. By the mid-1990s, however, the situation had changed considerably and evolutionary psychology had developed into an evidence-based discipline, integrated with the biological sciences and drawing extensively on work in cognitive science. The picture of the human mind that has emerged since then is one of a rich culturegenerating mechanism comprised largely of specialized modules that evolved to solve specific adaptive problems. Instead of being a 'blank slate' the mind/brain consists largely of evolved domain-specific modules that process information and generate representations about particular problems. ${ }^{9}$ The operation of these modules is inaccessible to consciousness though the results are often available for conscious consideration. They work automatically and very swiftly to produce intuitive representations about, for example, persons, artefacts, other minds or the physical world. At some level, still the subject of debate, integration of the modules' outputs occur so that the individual can form complex beliefs about the world without having to do so consciously. ${ }^{10}$ Conscious thinking is extremely valuable and adaptive in many ways but it is slow and error-prone so that if everything had to be worked out consciously humans would not survive. Similarly, if human children had to learn everything they needed to know about the world they would not be able to function. Instead they have significant cognitive architecture before they acquire language or culture that enables them, for instance, to make inferences about the properties of solid objects, recognize faces and then rapidly develop sophisticated skills in their early years such as the ability to attribute beliefs and desires to other persons. Persons are so significant in adaptive problems that a large proportion of the systems are dedicated to representing agents. ${ }^{11}$

These modules have content that is best understood as providing a template so that when a small piece of information activates a module many implicit expectations about that category are triggered to form complete representations. This is important because cultural transmission is quite sparse. Most of what a person needs to know is not actually part of what is transmitted by other people. So, for example, when a child finds out that cats are animals she does not have to be told all the information people take for granted such as that a cat moves by itself and cannot change into something else. When she learns that an object is a spanner she does not have to be told (and is unlikely to be told) that it cannot move by itself. She also knows that it can cease to be a spanner if its properties are altered. ${ }^{12}$ 
Biology enables culture to arise and it also constrains the content of that culture according to the structures of the mind. So, for example, humans are highly responsive to stimuli suggesting the presence of other agents. Because it is adaptive to be over-responsive to agency rather than under-responsive humans tend to posit agent-causes for natural phenomena and to look for intentional rather than mechanistic explanations of events. As Guthrie has put it, humans see faces in the clouds. ${ }^{13}$ These tendencies are, thus, widely reflected in human cultures across the world. They have direct implications for religious belief, as I shall show.

Cupitt was wrong about the role of culture in sustaining perception, cognition and emotion. These functions are present in working order before a child has any language and a rudimentary sense of self precedes language. His reliance on language and consciousness is undermined by the emerging view of the specialized mind and also by studies from neuropathology that show the independence of consciousness and language. Adults with various, sometimes profound, linguistic impairments from illness or injury show no impairment of consciousness suggesting that the biological sources of consciousness are not connected to language abilities. ${ }^{14}$ More significantly, Cupitt could not account for the skill with which languageless adults, often those who were born deaf and never had the chance to acquire sign language, find their way about the world. Although these people struggle with abstraction their consciousness is intact and they can perform an impressive range of cognitive tasks. ${ }^{15}$

The most interesting feature of the work in evolutionary psychology for the purposes of this paper is the evidence showing that religious beliefs in supernatural agents follow similarly universal patterns. As a species humans tend to over-populate the world with agents, as I have already mentioned, and some of the most salient of agent concepts are those that are usually labelled religious. A salient concept is one that is memorable and likely to spread easily. Boyer argues that religious concepts arise as a by-product of the operation of cognitive modules that evolved to do other things. The agency and animacy systems are activated but so are the social exchange mechanism, intuitive morality and sometimes the contagion module. That means that religious concepts tend to be about persons who are self-motivating, able to engage in social contracts with others involving exchange for mutual benefit and who have a particular interest in the moral concerns of the believers. The contagion module, which usually functions to prevent contact with dangerous substances such as decaying carcasses, is the source of religious notions of pollution and purity. The most successful representations are those that generate the most inferences for the least cognitive effort. That is, given a small amount of information from the outside an individual comes up with the most complete representation possible that solves the problem 
without conscious construction. Successful religious concepts tend to be those that have many or all of the features listed above and can be used as explanations of such things as misfortunes befalling individuals. ${ }^{16}$

Religious concepts are successful because they activate a range of modules producing intuitively plausible representations about matters that are socially important. They are part of a range of supernatural concepts such as ghosts or aliens that are universally found but they are distinguished by the fact that they matter deeply to people. They have an emotional component that other supernatural concepts lack. ${ }^{17}$ Spontaneously generated religious concepts contain at least one counterintuitive element. By counter-intuitive Boyer means something that contradicts the expectations that go with the object's ontological category. God, gods, spirits and ancestors fit the person-template, which means that people will automatically expect them to be able to do all that things that persons do such as enter into mutually beneficial social exchange arrangements, know all the things that a person knows, be interested in what persons are interested in and be limited in the way that persons are limited. Religious concepts are made salient by having an extra 'tag' to them, which represents a specific violation of a small number of those intuitive expectations. Too many violations would make the concept cognitively inefficient because they are too difficult to remember and work with; too few would make it lose salience. God is memorable because he is treated as a person but unlike other persons he can be everywhere at once. (Persons normally have a spatio-temporal location.) Because the concept of God activates the person template he is automatically taken to have intentions, an interest in the concerns of humans, a view on moral matters and an ability to enter into agreements. ${ }^{18}$

Not only persons can be sacred. Artefacts can become salient religious objects by having person-like characteristics attributed to them. Statues that can hear, think and respond to requests are not uncommon religious concepts. ${ }^{19}$

These recent developments in biological psychology do not establish a case for biological or genetic determinism - anathema to most evolutionary biologists and psychologists because they crudely misrepresent the complex interaction between nature and the environment - but do show that the human mind consists of an immensely sophisticated set of inference systems whose intricate workings enable every aspect of human functioning. Most of what Cupitt would attribute to culture is part of that biological function. Yet there remains the puzzle of why Cupitt does not recognize the value of this work for his own project since he is by far the most biologically literate philosopher of religion among his contemporaries. It is worth looking at this anomaly in more detail. 


\section{CUPITT AND EVOLUTIONARY PSYCHOLOGY}

Cupitt sets out his commitment to biological naturalism in The Last Philosophy ${ }^{20}$ where he puts forward a biologically informed psychology. There is considerable content to this psychology and it is Darwinian (or post-Darwinian) in that it relies heavily on evolutionary theory. By 1995 the literature on evolutionary psychology was both large and credible but Cupitt does not use it to refine his view of human psychology. He does not ignore it entirely, however. He cites Dawkins, the biologist who has popularized the notion of the 'selfish gene', and Pinker, whose work on language plays a dominant role in the evolutionary psychology programme. ${ }^{21} \mathrm{He}$ dismisses them both because, as a non-realist, he rejects their claim to have discovered something about the way the world works. In his most anthropological work, After All, he uses the work of Mithen, a palaeo-anthropologist who studies the evolutionary origins of religion. ${ }^{22}$ Unfortunately Cupitt misinterprets him.

Cupitt views all contemporary anthropology through his culturalist, global non-realist lens. Mithen is interested in the evolutionary origins of the universal tendency to develop religious belief, which he believes can be traced through the record of pre-historical human artefacts. His results apply to all humans and the relevant change in the species occurs in evolutionary time not historical time, between 30000 and 60000 years ago. ${ }^{23}$ Cupitt is committed to the view that significant changes in human nature - particularly human consciousness - occur during historical epochs even though there is no evidence of evolutionary change in humans in that timescale. Humans have the same minds now as they did in palaeolithic times. It is then, at least in part, Cupitt's culturalism that obscures his view of the recent revolution in the biological sciences. For him culture does all the work of transforming a rough and ready biology into something distinctively human. It is difficult to see how culture could be doing the work given that the capacity of the mind to support particular cultural structures has to exist prior to the cultural phenomena themselves. Cupitt has cultural change causing changes not just to the content of human minds - a modest and reasonable claim - but to the structure of the mind. In having the causal direction go from culture to mind Cupitt creates a mystery about how culture ever gets going. Mithen's account of how the mind evolved to make religious representations possible fills the explanatory gap and reverses the causal direction from mind to culture: once the cognitive capacity is present the forms cultures take will of necessity be consistent with that biologically based capacity.

A further problem is that Cupitt's culturalism supports his global nonrealism so that any scientific advance in any field can be dismissed by him as just another story about the world that is no more likely to be right than any other. There is no independent external reality against which 
one can test one's theories. He thinks scientists are profoundly mistaken when they take their discoveries to be about the world as it really is.

Instead he advocates a position that fits with the strong programme in the sociology of scientific knowledge; that is, the view that scientific knowledge itself is socially constructed. This is not the trivially true claim that sociological factors affect the course of scientific discovery but the claim that the discoveries themselves have only social causes.

Evidence of Cupitt's commitment to the strong programme within the sociology of scientific knowledge is scattered throughout his work. He claims that scientific theories are cultural products in a passage that suggests that theories, moral judgements, sense-data, rational intuitions and religious experiences are cultural products only (Creation, p. 26). They are not about anything real. Science 'privileges itself' but it is just a 'cultural construction' and scientists are revealed by the history of science to be 'cultural policemen' (Creation, pp. 168-169). Cupitt's view that language creates rather than merely describes the world leads him to reduce scientific observation to a literary activity that is to be regarded with the utmost suspicion. Data are 'hand-picked' because of their relationship to theory and they have been 'acculturated' because they can be presented only in a system of signs. They are entirely textual so that 'all science is literary and social. It cannot pretend to be itself natural in the sense of having a privileged and impartial standpoint outside language and culture' (Story, pp. 144-145). Of course, scientists have never claimed to be operating outside language or culture but they have argued that the results of their activity transcend language and culture and are true or false independently of cultural beliefs. An examination of the evidence put forward by sociologists of scientific knowledge actually shows the opposite of what they claim. Far from being culturally conditioned, science is robustly transcultural. ${ }^{24}$ But Cupitt requires science to be disarmed so that he cannot be shown to be wrong. The result is that he has entirely insulated himself from having to consider the possibility that research in biology undermines his central claims about human nature.

If evolutionary psychology is right about the evolved structures of the mind then Cupitt's culturalist assumption that language and culture create the mind is wrong. Rather, language and culture are biological categories that are dependent on the biology of humans and play a proximate causal role in the generation of the content of human culture but not an ultimate independent one. That is, the reason why a person is Catholic rather than Hindu may be explained by the cultural content of her local environment. The reason there are religious beliefs in the culture at all is due to specific features of the mind that make it possible for them to occur. Cupitt did not see the potential in evolutionary psychology and he attached religious non-realism to the soon to be discredited culturalism. This is a great shame because his biological naturalism is fundamentally right and if he had not covered it in layers of relativism 
and post-modernism he might have seen where it could lead. The unfortunate result is that religious realists have been able to dismiss the case for a non-realist interpretation of religious belief by disposing of culturalism. In the next section I shall show how taking biological naturalism seriously restores religious non-realism as a credible option for the interpretation of religious belief.

\section{BIOLOGICAL NATURALISM AND EVOLUTIONARY PSYCHOLOGY}

Several points follow from accepting biological naturalism and taking it to the conclusions about religion from which Cupitt was distracted by his culturalism. A biological naturalist accepts that the human mind is the product of evolution by natural selection and that the mind consists to a large extent of perceptual and cognitive modules designed by natural selection to solve adaptive problems, those that ultimately affect survival and reproduction. As a vast number of adaptive problems facing humans involve dealings with other humans, a large amount of cognitive architecture is dedicated to representing agency, keeping track of relationships and negotiating social exchanges for mutual benefit. These capacities are universal among humans and only the content of the representations changes according to culture. That is to say, humans have, for the last 30 000-60 000 years, inhabited the same mental and emotional world regardless of time and circumstance. Cultural differences are not structural. This universal structure of the mind both enables and constrains the type of culture humans can have.

Religious beliefs are also found universally among humans. The content varies but the pattern of beliefs is recurrent. That is, the same sorts of religious beliefs appear over and over again in the anthropological record. Given the potential for variety among religious beliefs, which we might expect to find about absolutely anything we can imagine, the record of the religious beliefs that people actually have is oddly narrow. ${ }^{25}$ They tend to be about supernatural agents who interact with people. They include rituals surrounding the most important aspects of life: birth, death and marriage. They contain representations of agentcauses of suffering and misfortune. ${ }^{26}$ Most people have some religious beliefs. And this recurrent pattern leads to the first point that the biological naturalist can entertain: religious beliefs in supernatural agents are natural. The biological naturalist can show that far from being a symptom of psychopathology or immaturity religious belief is a normal feature of human cognition. This finding is quite inconsistent with Cupitt's frequently repeated claim that 'we' cannot believe in these entities any more (because we are so different from our ancestors) and that it is a feature of mature adulthood to reject the needy, infantile dependence on a superbeing that has characterized Christianity. Rowan 
Williams has pointed out the use of 'we' is 'a claim to power and legitimacy of a kind'. ${ }^{27}$ Now there is some empirical evidence to suggest that Cupitt has misunderstood the nature of religious belief, not only in assuming it to be a sign of immaturity and cowardice but in failing to appreciate the function of its supernatural elements. That somewhat undermines his implicit claim to legitimacy.

The second point is that it is difficult to hold religious beliefs. People in the modern Western world are ambivalent about them. Cupitt is right to note that. However, he is mistaken in thinking that our ancestors found it easy to hold to religious beliefs. It has always been difficult to have religious beliefs. As I have explained, they are inherently counter-intuitive so are salient but always puzzling. Religious beliefs feel right to believers because they trigger a number of modules that operate below the level of consciousness whose job it is to produce the representations that make the richest inferences. On that level religious beliefs work very well. However, due to their essential counter-intuitive elements, conscious contemplation of religious beliefs draws attention to their inconsistencies. Bread and wine is still bread and wine at the same time it is meant to be flesh and blood; pigs sacrificed to the ancestors are eaten by the people doing the sacrifice not the ancestors. ${ }^{28}$ The result is ambivalence. Cupitt seeks to resolve the difficulty by removing the counter-intuitive element but does not realize that doing so changes religious belief into something else.

Religious rituals are also subject to ambivalence because the way they bring about their effects is opaque to participants and observers alike. Paul and Sandi are married after the ceremony even though they were recognized as a couple before it; boys who do not undergo tribal initiation rites still grow into men but are not like the ones who did undergo them; no one can quite explain how the ritual makes a difference or what that difference is. ${ }^{29}$ It is not the case that twenty-first century Westerners have become unable to hold beliefs that their less sophisticated ancestors held without difficulty. That means that one of Cupitt's central tenets is contradicted by the evolutionary anthropological evidence. It is not the case that religious belief is in radical need of reform because it has become impossible to believe. Reform may be necessary and, to an extent, possible but the criterion for revision of beliefs cannot be that they are difficult to believe because that encompasses all religious beliefs.

The post-Cupittian biological naturalist is in the position of being able to regard religious beliefs as benign or, at the very least, neutral because they are a part of the normal operation of human psychology. They are not delusional or in any other way pathological except in cases of mental illness. The biological naturalist can also recognize the inherent difficulty of holding religious beliefs though some people are more affected by this problem than others. Only the question of interpretation remains. Is there any constraint on how the biological naturalist may interpret religious 
belief? In the next section I shall explain that the answer to this question is no.

\section{THE INTERPRETATION OF RELIGIOUS BELIEF}

Dawkins, along with many other evolutionary biologists and psychologists, assumes that evolutionary theory shows that theism is false. ${ }^{30}$ However, the most it could show is that there is no evidence for the existence of God (not that there is no God) and then the argument applies only to certain conceptions of God that function as hypotheses about the natural world. Dawkins can easily explode fundamentalist interpretations of the creation stories but for theists who quite properly do not treat religious beliefs as hypotheses or explanations of the natural world he has a less adequate response.

Barrett, whose evolutionary psychology is very similar to Boyer's, regards the ease with which young children acquire the concept of God as evidence for the existence of God. ${ }^{31}$ Unfortunately, children in polytheistic cultures acquire polythesim with the same ease. Boyer carefully does not comment on the truth or falsity of religious beliefs as he does not think evolutionary psychology has anything to add about their truth status. ${ }^{32}$ His work leaves open the possibility of a non-realist interpretation as there is nothing in the theory that says religious beliefs have to be regarded as referential. There is, however, rather a lot of work required to show that non-realism is correct.

I argue that the theoretical developments in evolutionary psychology since Cupitt began writing can support religious non-realism and that this is the line Cupitt should have taken given that he claims to be a biological naturalist. He should have abandoned the culturalism of his earlier work once it became clear that the empirical foundations for it were unsound. In its place there are robust findings that support the notion that religious belief is a natural part of the human condition and that it is both normal to have religious beliefs and difficult to have them because they are counter-intuitive. Non-realists have always sought to preserve what is good about religious beliefs and the psychology of religion suggests that what is good about them is that they express deep features of human life, the most socially important aspects of it, in ways that are not reducible to anything else. Cupitt began with a desire to preserve the community's religious expressions but he did not realize that an essential element of that expression is precisely those aspects of belief that are most difficult to accept.

The non-realist does not have to take unjustified steps in either the direction of atheism or of theism on the basis of evolutionary theory. It is also possible to avoid the barrenness of agnosticism. The evidence from evolutionary psychology supports the view that the capacity for religious 
belief is a by-product of the evolution of capacities to represent agency. If modules are producing representations of the features of the world that they evolved to represent there is a criterion for determining the truth or falsity of those representations. That assumes that for the most part with some exceptions - the beliefs we hold as a result of the performance of the proper function of evolved mechanisms are truth-tracking. There are grounds for thinking that this is so. ${ }^{33}$ If, however, the modules are producing other sorts of representations as well, such as religious beliefs, that they did not evolve to represent then we have no grounds for assuming that those representations track some feature of the world external to ourselves. That creates a space for non-realism with respect to religious beliefs. It is possible to argue that religious beliefs are not truth-apt.

The attractions of a biologically based form of religious non-realism are considerable. The evolutionary psychological account of religious belief restores its respectability as a normal, if not entirely consistent, part of human life and strengthens the claim that it is socially important and irreducible.

The temptation to remove the inconsistencies in religious belief so that people can more easily assent to it is a strong one but in the end futile as consciously accepted revised beliefs have to compete with the operation of unconscious inference systems that pay attention to what is salient and generate representations that are essentially counter-intuitive. Removing the anomalies removes what makes religious belief different from other sorts of belief and also reduces the likelihood that people will pay attention to it or base any form of communal activity on it. Non-realists, however, can accept that ambivalence about religious belief is a normal state and not something that has to be fixed by revising the beliefs. They can remove the focus from whether religious beliefs are true to what meanings they express. These meanings are inexhaustible as religious belief draws on every facet of human functioning and remains ultimately impenetrable. There is scope for a rich variety of useful interpretations and for accepting that religious rituals can be profoundly expressive without having to be entirely transparent.

A further advantage of a biologically based non-realism that takes seriously the nature of religious belief is that it is in a better position for dialogue with religious realists because it recognizes that realist interpretations come naturally and should not be disparaged. There is room for debate about the scope of non-realism and possible combinations of realist and non-realist interpretations of religious beliefs. There is also common ground between realists and non-realists when it comes to the matter of reforming belief and practice because they share ethical concerns. There is nothing in such a form of religious non-realism that says 'anything goes'. The criteria for acceptability of belief and practice are ethical, as they often are for religious realists. Religious beliefs can to 
a degree be modified and have been by all believers. Not all the moves have been ethically sound but many of the liberal positions in Christian theology are ethically grounded. It is not the case that religious nonrealism occupies the high ground morally (contra Cupitt). For Christian non-realists the Gospel remains the reference point for evaluating practices as it does for realists. They both ask whether religious practices and religiously based positions reflect the Gospel values at the heart of the faith. Their answers may well be similar once Cupitt's denigration of religious belief has been removed.

Religious realists may well not like religious non-realism but they should object to it on different grounds than they have in the past. I argue that it is not so easily disposed of once the biological naturalist strand in Cupitt is set apart from the culturalism and developed as I have begun to do in this paper. At the very least it should now be taken seriously in a continuing conversation between religious realists and non-realists.

\section{CONCLUSION}

I have argued in this paper for a version of religious non-realism that originates in a neglected aspect of Cupitt's own work - neglected by him as well as by the commentators. It is founded on a commitment to evolutionary biology as it has developed into evolutionary psychology and related disciplines. Not only does this new field offer an account of the psychology of religious belief, it forms the basis for a non-realist interpretation of religious belief that recognizes the importance of those beliefs in human life and does not seek to reduce them to something other than they are. A biologically based religious non-realism rejects the discredited view of cultural causation of religious belief that lies at the heart of Cupitt's writing and does not require a commitment to global non-realism. Most importantly it restores the respectability of religious beliefs by showing that they are a normal part of human psychological functioning. With that understanding in place it is possible to map out a future for religious non-realism that does not fall into the trap of despising religious belief (or believers). It is possible now to appreciate the hold that religious realism has and to seek to work with realists rather than against them. ${ }^{34}$

\section{Notes}

1 Don Cupitt, Taking Leave of God (London: SCM Press, 1980).

2 Peter Byrne, God and Realism (Ashgate Philosophy of Religion Series) (Aldershot: Ashgate, 2003).

3 Ibid., p. ix. 
4 John Tooby and Leda Cosmides, 'The Psychological Foundations of Culture', in Jerome H, Barkow, Leda Cosmides and John Tooby (eds.), The Adapted Mind: Evolutionary Psychology and the Generation of Culture (New York: Oxford University Press, 1992), pp. 19-136.

5 Don Cupitt, Creation Out of Nothing (London: SCM Press, 1990), p. 106.

6 Don Cupitt, What is a Story? (London: SCM Press, 1991), p. 47 and p. 110.

7 Don Cupitt, Only Human (London: SCM Press, 1985), p. 169.

8 Peter Byrne, God and Realism, p. 28. Byrne uses the term 'global antirealism' to refer to the metaphysical thesis and 'non-realism' to refer to the disciplines such as science and theology.

9 John Tooby and Leda Cosmides, 'The Psychological Foundations of Culture', pp. 112ff.

10 See Dan Sperber, Explaining Culture: A Naturalistic Approach (Oxford: Blackwell, 1996), pp. 146-150; Steven Mithen, The Prehistory of the Mind: A Search for the Origins of Art, Religion and Science (London: Phoenix, 1998), pp. 211-222; Jerry Fodor, The Mind Doesn't Work That Way: The Scope and Limits of Computational Psychology (Cambridge MA: MIT Press, 2000), pp. $79-100$.

11 Pascal Boyer, Religion Explained: The Human Instincts That Fashion Gods, Spirits and Ancestors (London: William Heinemann, 2001), pp. 106-154.

12 Ibid., pp. 82-87.

13 Stewart Guthrie, Faces in the Clouds: A New Theory of Religion (Oxford: Oxford University Press, 1993).

14 Antonio Damasio, The Feeling of What Happens: Body and Emotion in the Making of Consciousness (New York: Harcourt Brace \& Co., 1999), pp. 107-112.

15 Oliver Sacks, Seeing Voices: A Journey into the World of the Deaf (London: Picador, 1991), pp. $45-53$.

16 Pascal Boyer, 'Religious Thought and Behaviour as By-Products of Brain Function', Trends in Cognitive Sciences 7: 3 (2003), pp. 119-124.

17 Ilkka Pyysiäinen, 'True Fiction: Philosophy and Psychology of Religious Belief', Philosophical Psychology 18: 1 (2003), pp. 109-125.

18 Pascal Boyer, Religion Explained, p. 73.

19 Ibid., p. 79.

20 Don Cupitt, The Last Philosophy (London: SCM Press, 1995).

21 Richard Dawkins, The Selfish Gene (Oxford: Oxford University Press, 1976); Steven Pinker, The Language Instinct: the New Science of Language and Mind (London: Penguin, 2000).

22 Don Cupitt, After All (New York: Basic Books, 1997).

23 Steven Mithen, Prehistory, p. 222.

24 For a thorough examination of the claims of sociologists of scientific knowledge and refutation of their positions see Robert Nola, Rescuing Reason: A Critique of Anti-Rationalist Views of Science and Knowledge, (Boston Studies in the Philosophy of Science) (Dordrecht: Kluwer Academic Publishers, 2003).

25 Pascal Boyer, Religion Explained, pp. 90-99.

26 Ibid., pp. 225-228.

27 Rowan Williams, 'Foreword' in Colin Crowder (ed.), God and Reality: Essays on Christian

Non-Realism (London: Mowbray, 1997), p. vii.

28 Pascal Boyer, Religion Explained, p. 277.

29 Ibid., pp. $294 \mathrm{ff}$.

30 See for example, Richard Dawkins, 'The Great Convergence' in A Devil's Chaplain: Selected Essays (London: Weidenfeld and Nicolson, 2003), pp. 146-151.

31 Justin Barrett, Why Would Anyone Believe in God? (Walnut Creek CA: Altamira Press, 2004), p. 108.

32 Pascal Boyer, Religion Explained, p. 55.

33 See for example David Papineau, 'The Evolution of Knowledge' in The Roots of Reason: Philosophical Essays on Rationality, Evolution and Probability (Oxford: Oxford University Press, 2003), pp. 39-82.

34 I am grateful to John Bishop, Denis Dutton and David Lumsden for comments on earlier versions of this paper. 